\title{
Is it safe? Talking to teens with HIVIAIDS about death and dying: a 3-month evaluation of Family Centered Advance Care (FACE) planning - anxiety, depression, quality of life
}

\author{
This article was published in the following Dove Press journal: \\ HIVIAIDS - Research and Palliative Care \\ 17 February 2010 \\ Number of times this article has been viewed
}

\author{
Maureen E Lyon' \\ Patricia A Garvie ${ }^{2}$ \\ Linda Briggs ${ }^{3}$ \\ Jianping $\mathrm{He}^{4}$ \\ Robert Malow ${ }^{5}$ \\ Lawrence J D'Angelo' \\ Robert McCarter ${ }^{4}$ \\ 'Children's National Medical Center \\ and George Washington School \\ of Medicine and Health Sciences, \\ Washington, District of Columbia; \\ ${ }^{2}$ St Jude Children's Research Hospital, \\ Memphis, Tennessee; ${ }^{3}$ Gundersen \\ Lutheran Medical Foundation, Inc., \\ Madison, Wisconsin; ${ }^{4}$ Children's \\ Research Institute, Washington, \\ District of Columbia; ${ }^{5}$ Florida \\ International University, Miami, \\ Florida
}

\begin{abstract}
Purpose: To determine the safety of engaging HIV-positive (HIV+) adolescents in a Family Centered Advance Care (FACE) planning intervention.

Patients and methods: We conducted a 2-armed, randomized controlled clinical trial in 2 hospital-based outpatient clinics from 2006-2008 with HIV+ adolescents and their surrogates $(\mathrm{n}=76)$. Three 60-90 minutes sessions were conducted weekly. FACE intervention groups received: Lyon FCACP Survey ${ }^{\mathcal{C}}$, the Respecting Choices ${ }^{\circledR}$ interview, and completion of The Five Wishes ${ }^{\odot}$. The Healthy Living Control (HLC) received: Developmental History, Healthy Tips, Future Planning (vocational, school or vocational rehabilitation). Three-month post-intervention outcomes were: completion of advance directive (Five Wishes ${ }^{\odot}$ ); psychological adjustment (Beck Depression, Anxiety Inventories); quality of life (PedsQL ${ }^{\mathrm{TM}}$ ); and $\mathrm{HIV}$ symptoms (General Health Self-Assessment).

Results: Adolescents had a mean age, 16 years; 40\% male; 92\% African-American; 68\% with perinatally acquired HIV, 29\% had AIDS diagnosis. FACE participants completed advance directives more than controls, using time matched comparison $(P<0.001)$. Neither anxiety, nor depression, increased at clinically or statistically significant levels post-intervention. FACE adolescents maintained quality of life. FACE families perceived their adolescents as worsening in their school $(P=0.018)$ and emotional $(P=0.029)$ quality of life at 3 months, compared with controls.
\end{abstract}

Conclusions: Participating in advance care planning did not unduly distress HIV+ adolescents.

Keywords: adolescents, advance care planning, communication, decision-making, family intervention, HIV/AIDS

\section{Introduction}

Most youth with HIV are now expected to live past 21 years, ${ }^{1,2}$ yet mortality rates are 30 times higher than for the general US pediatric population. ${ }^{3}$ In 2006 , in a perinatally infected cohort the mean age of death was 18 years. ${ }^{4}$ Overwhelming infection due to immune system compromise contributes to morbidity. ${ }^{4}$ Thus, incorporating advance care planning during the "antecedent period of decision making" may be valuable in preparing for end-of-life (EOL) care. Quality advance care planning includes discussing death, but differs from advance directives ${ }^{6}$ (ie, documenting who you want to make health care decisions for you when you can't make them for yourself, the kind of medical treatment you want or do not want). Concern about possible emotional distress has impeded families ${ }^{7,8}$ and providers from initiating

\footnotetext{
Correspondence: Maureen E Lyon Center for Clinical and Community Research, Children's Research Institute, George Washington University Medical School, Children's National Medical Center, Room 658, II I Michigan Avenue, N.W.,Washington, D.C. 20010-2970, USA $\mathrm{Tel}+\mathrm{I} 2024765442$

Fax +I 2024763630

Email mlyon@cnmc.org
} 
conversations regarding EOL for teens living with a life-threatening condition. ${ }^{9}$ Yet, talking about death and dying and decision-making with such teens may benefit them and their families. ${ }^{10-12}$ Teens want involvement in their own EOL decisions. ${ }^{13}$ Guidelines ${ }^{11,14}$ recommend conversations about advance care planning: 1) begin early or at diagnosis of a life-threatening condition; 2) be shared among the adolescent, family and health care provider; and 3 ) be routine and structured. Goals for EOL care frequently are unfulfilled, partially, because providers are concerned that talking about death and dying can provoke negative moods in the teen, ${ }^{15}$ as well as families. ${ }^{11,12}$ Our goal was to develop/adapt a structured, safe intervention that would provide an opportunity to talk about death and dying while medically stable: planning for the worst, hoping for the best.

Guided by a community-based participatory research framework, ${ }^{16}$ the Family Centered Advance Care (FACE) planning development and proximal outcomes are reported elsewhere. ${ }^{17,18}$ This report presents the 3-month FACE postintervention outcomes: plans and actions, psychological adjustment, and quality of life. The FACE intervention is based on Leventhal's theory of self-regulation ${ }^{19-21}$ and Folkman and Lazarus's theory of transactional stress and coping $^{22}$ (See Figure 1), postulating that interventions can change the appraisal of an illness from a death threat to a challenge with potential for growth and mastery.

We hypothesized that at 3 months, post-intervention families in the FACE intervention study would be significantly more likely to: 1) complete an advance directive (AD); 2) maintain or have improved psychological adjustment; 3) maintain or have enhanced quality of life; and 4) maintain or decrease HIV symptom severity, compared to families in the Healthy Living Control (HLC) time-matched comparison.

\section{Patients and methods}

\section{Participants}

Between July 1, 2006 and May 31, 2008, 40 HIV-infected adolescents and 40 adult surrogates $(n=80)$ were recruited from the Children's National Medical Center (CNMC) and St. Jude Children's Research Hospital (SJCRH) outpatient adolescent HIV specialty clinics. Recruitment criteria for adolescents included: aged 14-21 years, with an available legal guardian (if under 18 years) or adult surrogate at least

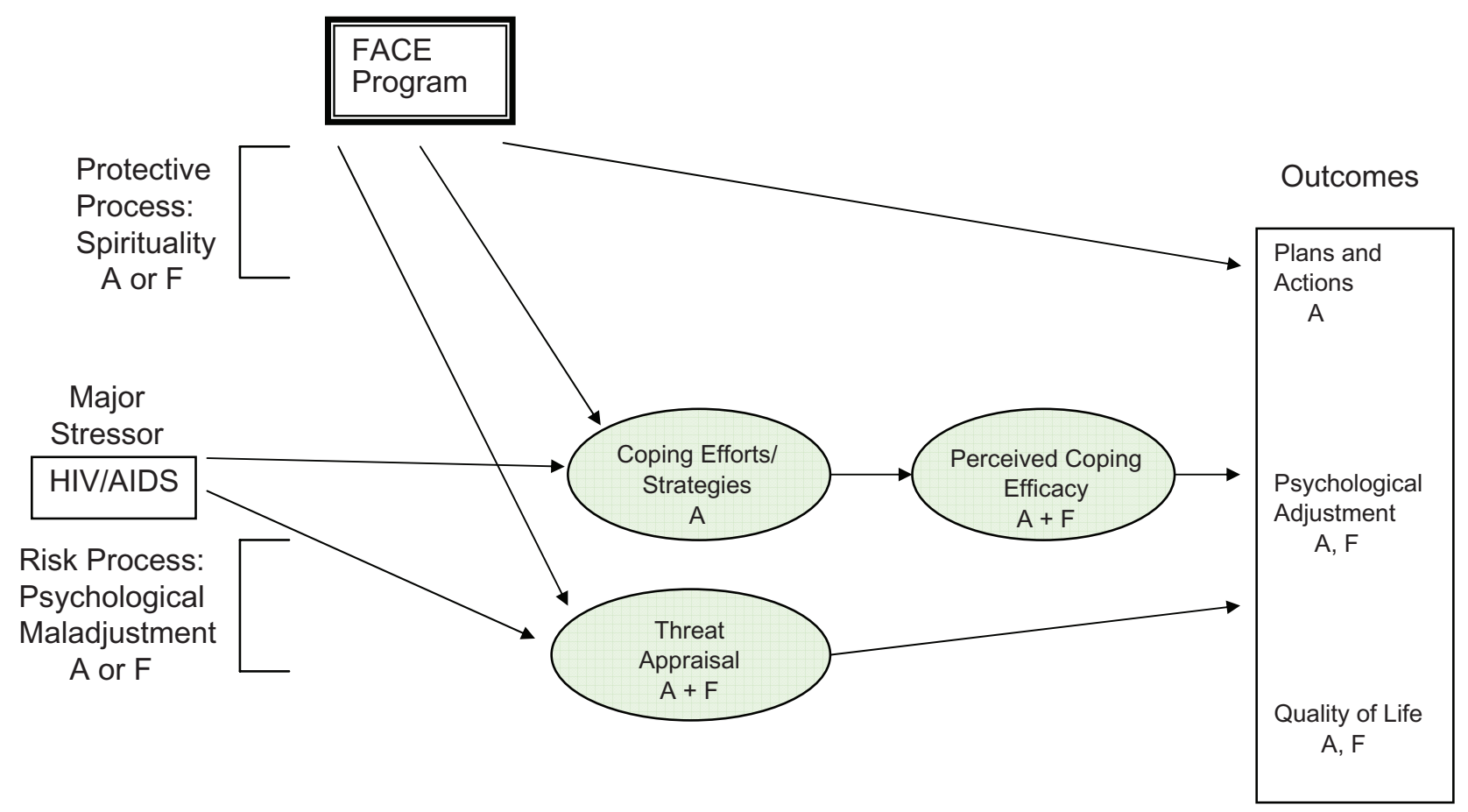

Figure I Transactonal model of coping with stress.

Notes: Proximal program mediators are shown in shaded areas.

Plans and Actions $=$ statement of treatment preferences and completion of Five Wishes ${ }^{\odot}$ advance directive.

Psychological Adjustment = Symptoms of depressed or anxious mood as measured by the Beck Depression Inventory II or the Beck Anxiety Inventory.

Quality of Life = Total, School, Emotion, Physical and Social quality of life as measured by PedsQL TM; HIV Specific Symptoms as measured by the General Health Assessment for Children.

Abbreviations: A, adolescent; F, family; FACE, Family Centered Advance Care. 
21 years old who knew the adolescent's HIV status, not in foster care, no developmental delays, severe depression, suicidal or homicidal ideation, dementia or psychosis. ${ }^{23-26}$ Additional family members were permitted to participate, however, their data were excluded from analyses. The FACE study was Institutional Review Board approved at both institutions. All participants provided written assent/consent.

\section{FACE intervention and healthy living control (HLC)}

Full details of the study methods are reported elsewhere. ${ }^{17,18}$ In brief, three 60-90 minute semi-structured family interview sessions were conducted by a trained/certified interviewer at weekly intervals: Session 1: Lyon Advance Care Planning Survey $^{\odot}$ - Adolescent and Surrogate Versions: Session 2: The Respecting Choices Interview ${ }^{\circledR}$ Session 3: Completion of The Five Wishes. ${ }^{\circ}$

HLC subjects were also administered in three weekly 60-90 minute sessions and family format to control for time, attention and/or related Hawthorn effects. Session 1: Developmental History. ${ }^{27}$ Session 2: Safety Tips. ${ }^{28}$ Session 3: School and Career Planning interview. ${ }^{29}$

\section{Outcome measures}

Five Wishes $^{\odot}$ (Towey and Aging with Dignity) is a legal document that facilitates expression of treatment preferences, if they were unable to communicate their wishes and includes the selection of a surrogate decision-maker. It can also serve as a tool to facilitate the participation of adolescents under age $18,{ }^{30}$ but must be signed by their parent/legal guardian to be legally sufficient.

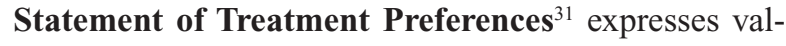
ues and goals related to future decision making regarding frequently occurring scenarios common to individuals with complications of AIDS. ${ }^{32}$ It was used to document specific treatment preferences of patients and their surrogates' understanding of what the patient would want. Patients and surrogates chose one of three options, "to continue all treatment and keep fighting," "to stop all treatment to prolong my life," and "don't know."

Beck Anxiety Index (BAI) ${ }^{24}$ is a 21 -item measure of anxiety rated on a 4-point Likert scale of symptoms over the past week. The BAI has demonstrated adequate reliability and validity to clinically assess anxiety in individuals aged 17 to 80 . We extended downward to age 14 to allow for consistency of data collected by a single measure of anxiety.

Beck Depression Inventory-II ${ }^{25}$ is a 21 -item scale self-report measure to assess presence of symptoms of depression over the past two weeks on a 4-point Likert scale for adolescents $>13$ years of age.

The Pediatric Quality of Life Inventory ${ }^{\mathrm{TM}} \mathbf{4 . 0}^{33-35}$ is a 23-item modular measure of health-related quality of life in children and adolescents. Four dimensions of functional quality of life (physical, emotional, social, school) are assessed. It has the strongest norms, validity, and reliability of the measures available. Norms exist for up to age 18.9 years, which was extended upward to allow for one assessment measure across participants.

General Health Assessment for Children ${ }^{36}$ is a selfreport measure for adolescents aged 12-20 years. The HIVrelated symptom subscale was used to assess the degree of distress caused by HIV-related physical symptoms. It is comprised of 18 items rated on a six-point Likert scale ("Not at All" to "Extremely").

Measures were administered separately to both the adolescent and surrogate, at baseline and at the 3-month postintervention follow-up.

Stage of Illness was measured by the CDC (Centers for Disease Control and Prevention) classification system in place at the time of the study. ${ }^{37}$

\section{Study design/data collection}

Adolescent/surrogate dyads were randomly assigned to one of two study groups, FACE versus HLC. Randomization utilized permuted block design, based on study site, to ensure the same numbers would be recruited to FACE and HLC. All participants were given a brochure with information on advance care planning and received standard of care. Follow-up data were collected face-to-face at 3-months postintervention with two exceptions. A research assistant, not the facilitator, administered follow-up questionnaires orally to control for literacy. Progress of participants through the trial is illustrated in Figure 2.

\section{Statistical analysis}

To assess whether the FACE intervention participants established an advance directive, medical charts were reviewed for documented completion.

Before we implemented parametric analyses, we evaluated the normality and variance homogeneity assumptions and when necessary implemented data transformations to ensure the data met these assumptions. Following analyses involving data transformations, the results were back transformed to return the estimates to their original scale and units. In this event, adjusted means are reported which also control for baseline levels of scores. 


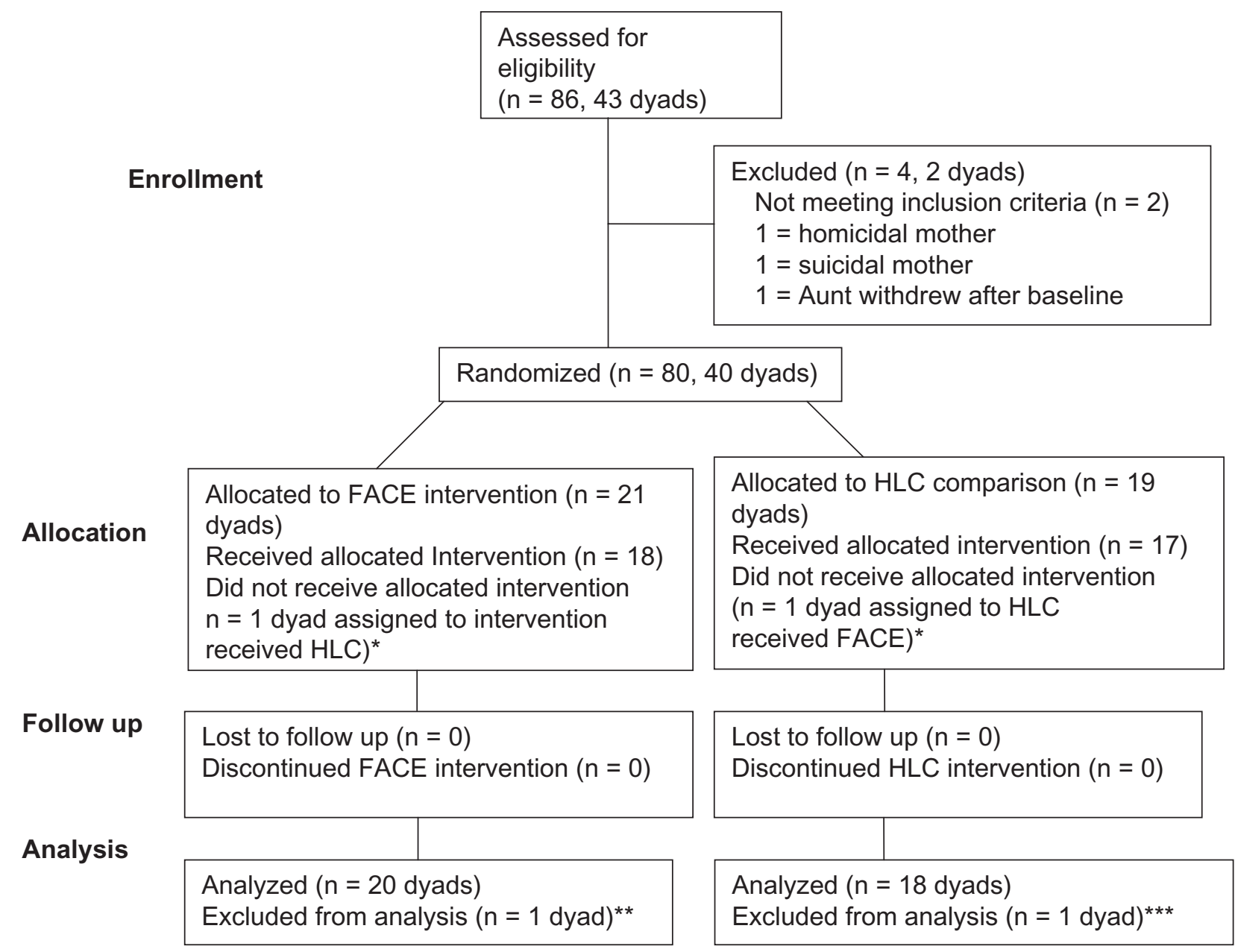

Figure 2 Flow of participants through each stage of the trial.

Notes: *Kept in analysis, per intent-to-treat design, as if received allocated condition; ${ }^{*} \mathrm{n}=\mathrm{I}$ randomized intervention adolescent became psychotic \& ineligible before Session I; $* * * \mathrm{n}=\mathrm{I}$ randomized adolescent control was shot \& withdrew from study before Session I.

To evaluate changes in psychological adjustment and quality of life, ANCOVA (analysis of covariance) was used to estimate and compare group means, with $95 \%$ confidence intervals, by study group and assess the effect of the two groups. Each estimate was derived controlling for baseline anxiety and depression scores, as well as any covariates found in preliminary analyses to differ between groups. The slope coefficient for group was used to estimate the magnitude of any differences. A $t$-test was employed to assess statistical significance.

In secondary analyses, logistic regression models were used to test for a trend in the outcome based on the level of severity of illness using CDC criteria. ${ }^{37}$ It was unnecessary to code for intervention exposure, because all subjects attended $100 \%$ of Sessions $1-3$. Estimates were derived separately for surrogate and adolescent. However, when possible, overall estimates were derived by treating the dyad as a cluster, again controlling for baseline levels, as well as any covariates found in preliminary analyses to differ between groups.

\section{Results}

\section{Sample characteristics}

Randomization produced an acceptable balance respecting group assignment by sample characteristics at baseline. ${ }^{17}$ Of eligible families, 97\% chose to participate. As planned, 40 dyads were randomized. However, two dyads were excluded from analyses due to withdrawal from the study prior to the start of Session 1. See Figure 2. Data analyses were based on 38 dyads, using an intent-to-treat design, which included the 2 misallocated dyads. The characteristics of these 38 adolescents are presented in Table 1. There were no adverse events.

\section{Plans and actions}

FACE adolescents completed the Five Wishes ${ }^{\odot}$ with their families at a higher rate than the HLC adolescents $(90 \%$ versus $11 \%, P<0.001$; Table 2$)$. At Baseline, one adolescent in the FACE group previously completed an AD and 5 were unsure whether they had. At 3-month post-intervention 
Table I 3-month post-intervention characteristics for family centered (FACE) and healthy living control (HLC) adolescents with HIV/ $\operatorname{AIDS}(\mathrm{n}=38)$

\begin{tabular}{|c|c|c|}
\hline $\begin{array}{l}\text { Adolescent } \\
\text { characteristics }\end{array}$ & $\begin{array}{l}\text { FACE intervention } \\
n=20\end{array}$ & $\begin{array}{l}\text { HLC group } \\
n=18\end{array}$ \\
\hline \multicolumn{3}{|l|}{ Age (in years) } \\
\hline Mean $( \pm S D)$ & $16.65( \pm 2.11)$ & $16.58( \pm 2.38)$ \\
\hline \multicolumn{3}{|l|}{ Gender } \\
\hline Males & $8(40 \%)$ & 7 (39\%) \\
\hline Females & $12(60 \%)$ & II (6I\%) \\
\hline \multicolumn{3}{|l|}{ Race/Ethnicity } \\
\hline Black/African American & 17 (94\%) & $18(90 \%)$ \\
\hline Non-African American & $\mathrm{I}(6 \%)$ & $2(10 \%)$ \\
\hline \multicolumn{3}{|l|}{ Mode of HIV Transmission } \\
\hline Perinatal infection & $15(75 \%)$ & II (6I\%) \\
\hline Behavioral infection & $5(25 \%)$ & 7 (39\%) \\
\hline \multicolumn{3}{|l|}{ CDC classification' } \\
\hline A I-3 (asymptomatic) & $5(25 \%)$ & II (6I\%) \\
\hline B I-3 (symptomatic) & $6(30 \%)$ & $5(28 \%)$ \\
\hline C $2-3^{2}$ (AIDS) & $9(45 \%)$ & $2(11 \%)$ \\
\hline \multicolumn{3}{|l|}{ Education } \\
\hline No High School Diploma/in HS & $12(60 \%)$ & $10(56 \%)$ \\
\hline HS or GED equivalent & $4(20 \%)$ & $6(33 \%)$ \\
\hline Some college/no bachelors & $4(20 \%)$ & $2(11 \%)$ \\
\hline \multicolumn{3}{|l|}{ Income } \\
\hline$\leq$ Federal poverty line & $7(35 \%)$ & $6(33 \%)$ \\
\hline $100 \%-200 \%$ of Federal poverty line & $\mathrm{I}(5 \%)$ & $3(17 \%)$ \\
\hline $201 \%-300 \%$ of Federal poverty line & $4(20 \%)$ & $4(22 \%)$ \\
\hline$>300 \%$ of Federal poverty line & $6(30 \%)$ & $3(17 \%)$ \\
\hline Unknown & $2(10 \%)$ & $2(11 \%)$ \\
\hline \multicolumn{3}{|l|}{ Housing status } \\
\hline Permanently housed & $18(90 \%)$ & 17 (94\%) \\
\hline Unstable living arrangement & $2(10 \%)$ & $\mathrm{I}(6 \%)$ \\
\hline \multicolumn{3}{|l|}{ Sexual orientation } \\
\hline Heterosexual & $17(85 \%)$ & $15(83 \%)$ \\
\hline Homosexual & I (5\%) & I (5.6\%) \\
\hline Bisexual & $2(10 \%)$ & $\mathrm{I}(5.6 \%)$ \\
\hline Don't know & $0(0 \%)$ & $\mathrm{I}(5 \%)$ \\
\hline \multicolumn{3}{|l|}{ Marital status } \\
\hline Single & $19(95 \%)$ & $17(94 \%)$ \\
\hline \multicolumn{3}{|l|}{ Married/Living } \\
\hline Together & $\mathrm{I}(5 \%)$ & $\mathrm{I}(6 \%)$ \\
\hline \multicolumn{3}{|c|}{ Length of time known diagnosis (in months) } \\
\hline Mean (SD) & $102.32( \pm 64.14)$ & $80.27( \pm 66.16)$ \\
\hline Range & $\mathrm{II}-220$ & $3-207$ \\
\hline \multicolumn{3}{|l|}{ Age learned HIV+ (in years) } \\
\hline Mean (SD) & $9.42( \pm 5.35)$ & $1 \mathrm{I} .5( \pm 5.2 \mathrm{I})$ \\
\hline Range & $0-18$ & $0-18$ \\
\hline
\end{tabular}

Notes: ${ }^{a}$ Data are from the old Centers for Disease Control and Prevention Classification system. ${ }^{37}$

'No patient had category $\mathrm{Cl}$.

Abbreviations: CDC, Centers for Disease Control and Prevention; (1992); GED, general educational development; FACE, Family Centered Advance Care planning intervention; HLC, healthy living control for time and attention, matched comparison group; SD, standard deviation. 
uncertainty was resolved. Five Wishes ${ }^{\odot}$ completion did not significantly differ by gender, race, ethnicity, education, employment status, CDC stage of illness, number of guardians present, length of time with known diagnosis or age at diagnosis. However, teens whose surrogates were not biological family members $(n=8 / 10 ; 80 \%)$ were more likely to complete the Five Wishes ${ }^{\odot}$ than those whose surrogates who were biological relatives $(11 / 28 ; 40 \%, P=0.031)$.

\section{Decision to stop extraordinary treatment}

On the Statement of Treatment Preferences the majority of adolescents chose to continue all treatments, regardless of quality of life. Ten percent of adolescents in Situation 1, 26\% in Situation 2, and $24 \%$ in Situation 3 chose to discontinue extraordinary treatment. FACE adolescents appeared to be no more likely than HLC adolescents to discontinue treatment across the three situations, but the absence of statistical significance in this small sample is not absence of an effect. See Table 2 . Non-African-American adolescents were significantly more likely to choose discontinue treatment $(P=0.026)$. A trend emerged for non-African-American adolescents to be more likely to discontinue treatment under Situation $2(P=0.060)$, if they were to become physically disabled and require nursing home care. No associations reached significance between the three Situations by gender, education, employment status, age, length of time known diagnosis or age learned HIV status.

\section{Psychological adjustment}

FACE adolescents who talked about their own prospective death and dying with their families in facilitated conversations by a trained facilitator were no more depressed or anxious than HLC adolescents at 3-months post-intervention (Table 3). Surrogates in the FACE group demonstrated slight increases in depressed and anxious mood compared to controls at 3-months post-intervention, controlling for baseline levels. However, increases were not clinically or statistically significant, but in minimal ranges and could be due to chance. Baseline levels of depression and anxiety predicted depression (adolescents, $P=0.002$; surrogates, $P<0.001$ ) and anxiety (adolescents, $P=0.003$; surrogates $P<0.001$ ) at 3-months post-intervention. Overall, adjusted mean levels of adolescent and surrogate depression and anxiety (Table 3 ) at 3-month post-intervention fell in the minimal clinical range. Depression and anxiety at 3-month post-intervention, controlling for baseline, did not differ significantly by gender, race, ethnicity, education, employment status, age at diagnosis, length of time with known diagnosis, family type or number of guardians present. Adolescents assigned to the intervention had statistically significantly higher depressed mood compared to controls at baseline, although mood levels were clinically insignificant in the minimal range.

\section{Quality of life}

Quality of life as measured by the PedsQL ${ }^{\mathrm{TM}}$ Total score was maintained for adolescents in both FACE and HLC and there

Table 2 3-month post-intervention outcomes: plans and actions

\begin{tabular}{|c|c|c|c|}
\hline \multirow[t]{3}{*}{ Outcomes } & FACE & HLC & \multirow[t]{3}{*}{$P^{+}$value } \\
\hline & FACE intervention & \multirow{2}{*}{$\begin{array}{l}\text { HLC comparison } \\
\mathrm{n}=18\end{array}$} & \\
\hline & $\mathbf{n}=\mathbf{2 0}$ & & \\
\hline Completed Five Wishes or other AD & $19^{a}(95 \%)$ & $2(11 \%)$ & $<0.001 *$ \\
\hline Statement of Treatment Preferences: & \multicolumn{3}{|l|}{ Stop all efforts ${ }^{+}$} \\
\hline Situation \#I & $3(15 \%)$ & I (6\%) & $0.187^{\mathrm{a}}$ \\
\hline Situation \#2 & $5(25 \%)$ & $5(28 \%)$ & $1.000^{\mathrm{a}}$ \\
\hline Situation \#3 & $6(30 \%)$ & $3(17 \%)$ & $0.528^{\mathrm{a}}$ \\
\hline
\end{tabular}

Notes: "“To stop all efforts to keep me alive (For me quality of life is more important than length of life). This includes such treatments as CPR, blood transfusions, kidney dialysis and tube feedings.

I. If I have serious complications from AIDS, such as an overwhelming infection or pneumonia, so that I was facing a long hospital stay, with many medical treatments AND my chance of living through this complication is low (for example, only 5 out of 100 kids will live), I would choose the following: (Whatever my choice, I want to be kept as comfortable as possible).

2. If I have AIDS and a serious complication, such as an overwhelming infection or pneumonia and have a good chance of living through this complication, but it was expected that I would never be able to walk or talk again, and I would need 24 hour nursing care, I would choose the following. (Whatever my choice, I want to be kept as comfortable as possible).

3. If I have AIDS and a serious complication, such as an overwhelming infection or pneumonia and have a good chance of living, but it was expected that I would never know who I was or who I was with and would need 24 hour nursing care, I would choose the following. (Whatever my choice, I want to be kept as comfortable as possible).

Notes: ${ }^{\mathrm{a} D a t a}$ are frequencies. I-sided Fisher Exact Test. I patient completed Five Wishes outside of one month post session window for protocol. No significant differences by perinatal vs behavioral transmission for completing advance directive, $P=0.284$.

*Significant at the $P=0.05$ level.

Abbreviations: CPR, cardiopulmonary resusication; FACE, Family Centered Advance Care Planning; EOL, end-of-life; HIVIAIDS, human immunodeficiency virus/acquired immune deficiency syndrome; HLC, healthy living control. 
Table 3 3-month post-intervention outcomes: psychological adjustment by treatment group controlling for baseline levels

\begin{tabular}{|c|c|c|c|}
\hline \multirow[t]{2}{*}{ Outcomes } & \multirow{2}{*}{$\frac{\text { FACE }(n=40)}{\text { Intervention }}$} & \multirow{2}{*}{$\frac{\text { HLC }(n=36)}{\text { Comparison }}$} & \multirow[t]{2}{*}{$\mathbf{P}^{+}$value } \\
\hline & & & \\
\hline \multicolumn{4}{|c|}{ BAl adjusted mean scores with upper and lower $95 \%$ confidence intervals (Range $0-63 ; 0$ to $7=$ minimal anxiety) } \\
\hline \multicolumn{4}{|l|}{ Adolescent } \\
\hline Baseline & $2.76(1.38-4.60)$ & $1.38(0.44-2.84)$ & 0.170 \\
\hline 3 month post-intervention & $2.48(1.14-4.34)$ & $1.06(0.24-2.45)$ & 0.149 \\
\hline \multicolumn{4}{|l|}{ Surrogate's own mood } \\
\hline Baseline & $1.64(0.62-3.14)$ & $2.5 I(I . \mid 4-4.4 I)$ & 0.395 \\
\hline 3 month post-intervention & $2.48(1.20-4.22)$ & $2.35(1.06-4.15)$ & 0.901 \\
\hline \multicolumn{4}{|c|}{ BDI-II adjusted mean scores** with upper and lower $95 \%$ confidence intervals (range 0-63;0-13= minimal depressed mood) } \\
\hline \multicolumn{4}{|l|}{ Adolescent } \\
\hline Baseline & $7.8(4.73-11.69)$ & $1.27(0.22-3.17)$ & $0.001 *$ \\
\hline 3 month post-intervention & $5.06(2.57-8.39)$ & $3.43(1.35-6.45)$ & 0.432 \\
\hline \multicolumn{4}{|l|}{ Surrogate's own mood } \\
\hline Baseline & $2.0(0.66-4.09)$ & $3.65(1.62-6.50)$ & 0.261 \\
\hline 3 month post-intervention & $2.73(1.26-4.77)$ & $3.29(1.57-5.65)$ & 0.676 \\
\hline
\end{tabular}

Abbreviations: BAI, Beck Anxiety Inventory; BDI-II, Beck Depression Inventory; 2nd Edition. Higher scores represent higher symptom levels. FACE, Family Centered Advance Care planning; HLC, healthy living control.

were not significant differences by group or on any of the subscales (Table 4).

However, surrogates' perception of their adolescents' Total quality of life was significantly lower for surrogates in the FACE versus HLC group $(P=0.032)$ at 3-months, controlling for baseline levels. FACE surrogates rated their adolescents as having poorer school quality of life at 3-months post-intervention (66.9 versus $80.0, P=0.011)$ and poorer emotion quality of life ( 74.8 versus $85.7, P=0.029)$, compared to HLC surrogates. The physical and social subscale scores were not significantly different by group, controlling for baseline levels.

\section{Quality of life - HIV specific symptoms}

On the GHAC trends towards more HIV-specific symptoms emerged in FACE vs HLC adolescents for the following symptoms (See Table 5): rash or itching; fatigue or weakness; and trouble sleeping. However, the scores reflect very low levels of symptoms, if examined using the midpoint cut-off for reporting symptoms which distressed them, moderately, very much or extremely. There were no statistically significant differences between FACE and HLC teens for any other HIV related symptoms 3-months post-intervention. There also was no relationship between Treatment Preferences and symptom score $(P=0.39)$.

In secondary analysis using a regression model examining all adolescents regardless of treatment arm, those in CDC
Category B (symptomatic, not AIDS) had lower physical scores (more symptoms) than those in Category A (asymptomatic) or C (AIDS) $(P=0.005)$ and they scored higher on Total Symptoms $(P=0.015)$.

Table 4 3-month post-intervention outcome: quality of life: PedsQL ${ }^{\mathrm{TM}}$ adjusted mean scores with $95 \%$ confidence intervals (ci upper and lower limits), controlling for baseline levels

\begin{tabular}{|c|c|c|c|}
\hline \multirow[t]{2}{*}{ Outcomes } & $\begin{array}{l}\text { FACE } \\
\text { Intervention } \\
\mathrm{n}=40\end{array}$ & $\begin{array}{l}\text { HLC } \\
\text { Comparison } \\
\mathbf{n}=36\end{array}$ & $\mathbf{P}^{+}$value \\
\hline & Adjusted Mean/CI & Adjusted Mean/CI & \\
\hline \multicolumn{4}{|l|}{ Adolescent } \\
\hline TOTAL & $338.5(321-355)$ & $345.6(327.3-363.1)$ & 0.568 \\
\hline Physical & $93.1(89.4-96.6)$ & $93.8(91.3-96.3)$ & 0.692 \\
\hline School & $75.0(68.4-82.0)$ & $77.7(70.7-85.2)$ & 0.589 \\
\hline Emotional & $82.0(74.8-88.6)$ & $82.5(74.4-90.0)$ & 0.921 \\
\hline Social & $90.3(86.5-93.9)$ & $92.0(88.6-95.2)$ & 0.297 \\
\hline \multicolumn{4}{|c|}{ Surrogate perception of adolescent quality of Life } \\
\hline TOTAL & $324.8(308.4-340.4)$ & $349.3(333.4-364.6)$ & $0.032 *$ \\
\hline Physical & $92.3(89.3-95.1)$ & $93.0(89.7-96.1)$ & 0.692 \\
\hline School & $66.9(60.0-74.1)$ & $80.0(72.1-88.3)$ & $0.018 *$ \\
\hline Emotion & $74.8(67.2-81.6)$ & 85.7 (78.9-92.0) & $0.029 *$ \\
\hline Social & 91.0 (88.0-93.8) & 92.7 (89.2-95.9) & 0.297 \\
\hline
\end{tabular}

Notes: *Significant at $P=0.05$. ${ }^{+}$All $P$ values control for baseline using a $t$-test to assess significance. Range of subscale scores is 0 tol00. Higher scores represent better quality of life.

Abbreviations: FACE, Family Centered Advance Care planning; HLC, healthy living control. 
Table 5 3-month post-intervention outcomes: quality of life-HIV specific symptoms:general health assessment for children HIV symptoms. Percentage of adolescents reporting moderately, very much or extremely distressed by symptom at 3-month post-intervention controlling for baseline levels of symptoms

\begin{tabular}{|c|c|c|c|}
\hline HIV specific symptoms & $\begin{array}{l}\text { FACE intervention } \\
n=20\end{array}$ & $\begin{array}{l}\text { HLC comparison } \\
n=18\end{array}$ & $P$ value \\
\hline Physical/bodily pain & $5 \%$ & $0 \%$ & 0.210 \\
\hline Coughing/Wheezing & $10 \%$ & $0 \%$ & 0.604 \\
\hline Nausea/vomiting & $5 \%$ & $0 \%$ & 0.737 \\
\hline Skin problems (rash, itching, etc) & $5 \%$ & $0 \%$ & $0.063^{+}$ \\
\hline Fatigue & $0 \%$ & $5 \%$ & $0.095^{+}$ \\
\hline Feeling dizzy/lightheaded & $5 \%$ & $0 \%$ & 0.178 \\
\hline Fever/night sweats/shaking/chills & $5 \%$ & $0 \%$ & 0.737 \\
\hline Loss of appetite & $5 \%$ & $0 \%$ & 0.663 \\
\hline Trouble sleeping & $0 \%$ & $0 \%$ & $0.058^{+}$ \\
\hline Eye trouble/problems with vision & $0 \%$ & $5 \%$ & 0.734 \\
\hline Headaches & $5 \%$ & $0 \%$ & 0.342 \\
\hline Dry or painful mouth/trouble swallowing & $0 \%$ & $0 \%$ & 1.0 \\
\hline Chest pain or tightness & $5 \%$ & $0 \%$ & 1.0 \\
\hline Difficulty breathing or catching breath & $0 \%$ & $0 \%$ & 0.656 \\
\hline Runny nose/sinus trouble & $10 \%$ & $0 \%$ & 0.479 \\
\hline Muscle aches/joint or bone pain & $0 \%$ & $0 \%$ & 0.232 \\
\hline Pain, numbness or tingling & $0 \%$ & $0 \%$ & 0.792 \\
\hline Overall discomfort & $0 \%$ & $0 \%$ & 0.697 \\
\hline
\end{tabular}

Notes: ${ }^{+} A$ Il $P$ values control for baseline using a $t$-test to assess significance at the 0.05 level.

Abbreviations: FACE, Family Centered Advance Care planning; EOL, end-of-life; HIV/AIDS, human immunodeficiency virus/acquired immune deficiency syndrome; HLC, healthy living control.

\section{Discussion}

Using a rigorous randomized 2-arm design and intent-to-treat analysis, the FACE intervention demonstrated that advance care planning can be safely administered to HIV+ teens, ie, did not cause significant emotional distress or adverse events. FACE prepared surrogate decision makers for their role in EOL discussions and treatment decisions.

Our study challenges earlier finding $\mathrm{s}^{38-47}$ with $100 \%$ of our primarily African-American FACE group completing an advance directive. The fact that several families spontaneously requested an extra copy of the Five Wishes ${ }^{\circ}$ to complete for themselves suggests this outcome was not a result of the Hawthorne Effect (desire to please the researcher). Our results are consistent with a report by Washington, who in a study of African-American primary caregivers who made decisions about EOL care, found strong support for hospice care..$^{48}$

Participating in the FACE intervention did not influence decisions to discontinue treatment. Our goal was to safely assist adolescents with HIV/AIDS to make decisions with their families about their EOL preferences, while still cognitively intact. ${ }^{49-51}$ People sometimes change their $\mathrm{AD}$ as the disease progresses, for example, deciding to "Allow a Natural Death," rather than to continue aggressive treatment(s). Thus, EOL care decision making is best understood as an ongoing process, rather than a one-time event, and should be revisited. ${ }^{52-57}$

Consistent with earlier adult studies ${ }^{44,45,58-61}$ AfricanAmerican adolescents in our cohort preferred to continue all treatments at EOL at rates significantly higher than non-African-American adolescents, however, because of our small sample size this result may not be stable. This finding differs from that of Hinds and colleagues ${ }^{62}$ who reported race did not influence DNR (do not resuscitate) status in a pediatric oncology sample. This difference could be due to the timing of decision making, which in the Hinds study was during what Hansen ${ }^{5}$ calls the "central period" of decision making (where EOL is eminent), rather than the "antecedent period" as was done in our study. Our African-American families were willing to think and talk about EOL issues and were prepared for their role as decision-makers. ${ }^{17,18}$ 
FACE achieved rates of recruitment in excess of those reported in adults in which only $30 \%-47 \%$ of eligible patients participated in EOL studies. ${ }^{63-66}$ Nevertheless, 54\% of potential participants approached prior to screening for eligibility, declined to participate. Dyadic/family studies pose a challenge as sometimes the patient wants to participate, but the family member does not have time, wants to protect the patient, or is uninterested. ${ }^{67}$

Several factors may explain the success of the FACE intervention. First, we integrated processes identified with successful HIV interventions, ${ }^{68-70}$ specifically, communitybased participation in development and adaptation to ensure cultural sensitivity and to reduce health disparities. ${ }^{16,17,71,72}$ Second, we used a competency-based program to ensure consistency in the delivery of the intervention as measured by two components: 1) facilitator certification and 2) patient and family ratings of quality of communication, consistent with the recommendations of Dickens. ${ }^{72}$ Third, the high rate of retention suggests participants were highly motivated to seek education and improve long-term care. Fourth, FACE was highly family-centered. Finally, research assistants were hired and retained only if they committed to flexibility in scheduling sessions and if successfully certified (Respecting Choices ${ }^{\circledR}$ interview).

In contrast to Bakitas and colleagues ${ }^{63}$ we did not find improvements in quality of life or mood for the intervention group, rather healthy levels of mood and quality of life were maintained. Floor effects for mood and ceiling effects for quality of life limited the power to detect differences, and differences that we found were within healthy ranges and therefore not clinically significant. The reason(s) higher levels of depressed mood were found at baseline for adolescents randomly assigned to FACE versus HLC are unclear. Baseline assessment occurred before randomization, so assignment to the intervention group did not impact mood.

Unexpectedly, FACE surrogates perceived their adolescents' school and emotional quality of life was lower compared to HLC surrogates. This may reflect increased knowledge of school related and emotional problems for their teens that emerged during the facilitated conversation. Also, FACE surrogates reported more sadness and anxiety at 3-month post-intervention, than FACE adolescents who reported less compared to baseline levels. Although the changes were not clinically or statistically significant, they suggest that adolescents may have found talking about their own death and dying less anxiety provoking and sad than their families did. This finding needs further study.

\section{Conclusion}

The FACE results begin to fill the gap on ethnocultural factors that influence EOL decision making and preferences among HIV-positive adolescents, who demonstrated a willingness to discuss difficult and emotionally-laden issues with their surrogate decision makers and complete advance directives, potentially "breaking the ice" for future EOL conversations. Going beyond measuring the effect of communication on satisfaction, we studied outcomes related to advance care planning, quality of life and mood using standardized measures. The FACE results suggest that research into this sensitive area is safe. Probable benefits at the time of dying for teens and families, or after death for families, remain to be demonstrated in future studies.

\section{Funding/support}

The study was funded by grant 5R34MH072541-03 from the National Institute of Mental Health. The content is solely the responsibility of the authors and does not necessarily represent the official views of the National Institute of Mental Health or the National Institutes of Health. This trial has been registered at www.clinicaltrials.gov Identifier \#NCT00723476.

\section{Acknowledgments}

We wish to thank our families for their participation and the community for their help in developing this protocol, especially Ebony Johnson. We also thank Connie Trexler and Keith Selden who facilitated the community advisory boards and focus groups. We extend our gratitude to our research assistants who worked with our families: Stephanie Lee, Portia Pieterse, Yolanda Peele, Ellin Kao, LaQuisha Mark, Mackenzie Nowell, Megan Banet, Megan L Wilkins, Ericka Midgett, J Christopher Young, Elizabeth Kolivas. We thank Jennifer Marsh and Saeid Goudarzi for help with statistical support and data management early in the study. We thank our consultants Drs Beatrice Krauss, Mary Ann McCabe, Bruce Rapkin and Robert Washington who helped during the developmental phase of the study and Dr Tomas Silber for his ethics consultations. We thank the health care providers and case managers who referred families to our study, especially Drs Hans Spiegel and Natella Rakhmanina.

\section{Disclosures}

Linda Briggs, receives royalties from the Respecting Choices $^{\circledR}$ interview. However, the remaining authors have no 
financial relationships or other conflicts of interest relevant to this article to disclose.

\section{References}

1. Justice AC, McGinnis KA, Skanderson M, et al. Towards a combined prognostic index for survival in HIV infection: the role of 'no-HIV' biomarkers. HIV Med. 2009;11(2):143-151.

2. McConnell MS, Byers RH, Frederick T, et al. Trends in antiretroviral therapy use and survival rates for a large cohort of HIV-infected children and adolescents in the United States, 1989-2001. Epidemiology and Social Science. 2005;38(4):488-494.

3. America's Children in Brief: Key National Indicators of Well-Being: 2008. Available at: http://www.childstats.gov/americaschildren.

4. Brady MT, Oleske JM, Williams PL, et al. Declines in mortality and changes in causes of death in HIV-1 infected children during the HAART era. J Acquir Immune Defic Syndr. 2010;(5391):86-94.

5. Hansen L, Archbold PG, Stewart BJ. Role strain and ease in decisionmaking to withdraw or withhold life support for elderly relatives. J Nurs Scholarsh. 2004;36(3):233-238.

6. Grady PA. Introduction: Papers from the National Institutes of Health State-of-the-Science Conference on improving end-of-life care. $J$ Palliative Med. 2005;8(Suppl 1):S1-S3.

7. Bearison D. They Never Want to Tell You. Cambridge, MA: Harvard Univ Press; 1991.

8. Bluebond-Langner M. Private Worlds of Dying Children. Princeton, NJ: Princeton University Press; 1978.

9. Hinds PS, Burghen EA, Pritchard M. Conducting end-of-life studies in pediatric oncology. West J Nurs Res. 2007;29:448-465.

10. Hinds PS, Schum L, Baker JN, Wolfe J. Key factors affecting dying children and their families. J Palliat Med. 2006;8:S70-S78.

11. Field MJ, Behrman RE, editors: When Children Die: Improving palliative and end-of-life care for children and their families. Washington, DC: Institute of Medicine, National Academy Press; 2002.

12. Walsh-Kelly CM, Lang KR, Chevako J, et al. Advance directives in a pediatric emergency department. Pediatrics. 1999;103:826-830.

13. Lyon ME, McCabe MA, Patel K, D'Angelo LJ. What do adolescents want? An exploratory study regarding end-of-life decision-making. J Adolesc Health. 2004;35(6):529 e1-e6.

14. American Academy of Pediatrics: Committee on Bioethics and Committee on Hospital Care. Palliative care for children. Pediatrics. 2000;106:351-357.

15. Kane JR. Pediatric palliative care moving forward: Empathy, competence, quality, and the need for systematic change. J Palliat Med. 2006;9:847-849.

16. Bogart LM, Uyeda K. Community-based participatory research: Partnering with communities for effective and sustainable behavioral health interventions. Health Psychol. 2009;28(4):391-393.

17. Lyon ME, Garvie PA, Briggs L, He J, D'Angelo L, McCarter R. Development, feasibility and acceptability of the Family-Centered (FACE) Advance Care planning intervention for adolescents with HIV. J Palliat Med. 2009;12(4):363-372.

18. Lyon ME, Garvie PA, McCarter R, Briggs L, He J, D’Angelo L. Who will speak for me? Improving end-of-life decision-making for adolescents with HIV and their families. Pediatrics. 2009;123(2): e199-e206.

19. Leventhal HH, Nerenz DR, Steele DJ. Illness representations and coping with health threats. In: Baum A, Taylor SE, Singer JE, editors: Handbook of Psychology and Health, Vol. IV: Social psychological aspects of health, A. New Jersey: Laurence Erlbaum Associates, Inc; 1984. p. 219-252.

20. Leventhal H, Diefenbach M. The active side of illness cognition. In: Skelton JA, Croyle RT, editors Mental Representation in Health and Illness. New York, NY: Springer Verlag; 1991:247-272.

21. Leventhal H, Benyamini Y, Shafer C; Lay beliefs about health and illness. In: Ayers S, editors: Cambridge Handbook of Psychology, Health and Medicine. Cambridge, MA: Cambridge University Press; 2007:124-128.
22. Lazarus RS, Folkman S. Appraisal, and Coping. New York, NY: Springer Publishing Company; 1984.

23. Power C, Selnes OA, Grim JA, McArthur JC. HIV Dementia Scale: a rapid screening test. J Acquir Immune Defic Syndr Hum Retrovirol. 1995;8:273-278.

24. Beck AT, Steer RA. Beck Anxiety Inventory Manual. San Antonio, TX: The Psychological Corporation, Harcourt Brace \& Company; 1993.

25. Beck AT, Steer RA, Brown GK. Beck Depression Inventory Manual (2nd edition). San Antonio, TX: The Psychological Corporation, Harcourt Brace \& Company; 1996.

26. King CA, Katz SH, Ghaziuddin N, Brand E, Hill E, McGovern L. Diagnosis and assessment of depression and suicidality using the NIMH Diagnostic Interview Scale for Children-DISC-2.3-National Institute of Mental Health. J Abnormal Child Psych. 1997;25(3):173-181.

27. Barkley RA. Attention-Deficit Hyperactivity Disorder: A clinical workbook. New York, NY. The Guilford Press; 1993.

28. American Academy of Pediatrics: Bright Futures. 2005. Accessed January 10, 2010. Available from: http://brightfutures.aap.org/web/ healthCareProfessionalstoolsAndResources.asp.

29. Wolf-Branigin M, Schuyler V, White P. Improving quality of life and career attitudes of youth with disabilities: Experiences from the Adolescent Employment Readiness Center. Res Soc Work Prac. 2007:17:324-334

30. Wiener L, Ballard E, Brennan T, Battles H, Martinez P, Pao M. How I wish to be remembered: the use of an advance care planning document in adolescent and young adult populations. $J$ Palliat Med. 2008;11:1309-1313.

31. Hammes BJ, Briggs L. Respecting choices: advance care planning facilitator manual. Includes Statement of Treatment Preferences. La Crosse, WI: Gundersen Lutheran Medical Foundation; 2000.

32. Watcher RM, Lo B. Advance directives for patients with Human Immunodeficiency Virus infection. Crit Care Clin. 1993;9:125-135.

33. Varni JW, Seid M, Rode CA. The PEDSQL: measurement model for the pediatric quality of life inventory. Med Care. 1999;37:126-139.

34. Varni JW, Seid M, Kurtin PS. PedsQL 4.0: reliability and validity of the Pediatric Quality of Life Inventory version 4.0 generic core scales in healthy and patient populations. Med Care. 2001;39:800-812.

35. Varni JW, Burwinkle TM, Seid M, Skarr D. The PedsQL ${ }^{\mathrm{TM}} 4.0$ as a pediatric population health measure: Feasibility, reliability, and validity. Ambul Pediatr. 2003;3:329-341.

36. Gortmaker SL, Lenderking WR, Clark C, et al. Development and Use of a Pediatric Quality of Life Questionnaire in AIDS Clinical Trials: Reliability and Validity of the General Health Assessment for Children. In: Drotar D, editors, Measuring Health-Related Quality of Life in Children and Adolescents: Implications for Research and Practice. Mahway, NJ: Lawrence Erlbaum Associates; 1998:219-235.

37. Centers for Disease Control and Prevention. 1993 revised classification system for HIV infection and expanded surveillance case definition for AIDS among adolescents and adults. MMWR: Recomm Rep. 1992;41:1-17.

38. Morrison RS, Zayas LH, Mulvihill M, Baskin SA, Meier DE. Barriers to completion of health care proxies: An examination of ethnic differences. Arch Intern Med. 1998;158:2493-2497.

39. Blackhall LJ, Frank G, Murphy ST, Michel V, Palmer JM, Azen SP. Ethnicity and attitudes towards life sustaining technology. Soc Sci Med. 1999;48:1779-1789.

40. Kiely DK, Mitchell SL, Marlow A, Murphy KM, Morris JN. Racial and state differences in the designation of advance directives in nursing home residents. J Am Geriatr Soc. 2001;49:1346-1352.

41. Degenholtz HB, Arnold RA, Meisel A, Lave JR. Persistence of racial disparities in advance care plan documents among nursing home residents. J Am Geriatr Soc. 2002;50:378-381.

42. Degenholtz HB, Thomas SB, Miller MJ. Race and the intensive care unit: Disparities in preferences for end-of-life care. Crit Care Med. 2003;31(5 Suppl):S373-S378.

43. Smith DB. Health Care Divided: Race and Healing a Nation. Ann Arbor, MI: The University of Michigan Press; 2002:24-27. 
44. Phillips RS, Hamel MB, Teno JM, et al. Patient race and decisions to withhold or withdraw life-sustaining treatments for seriously ill hospitalized adults. SUPPORT Investigators. Study to Understand Prognoses and Preferences for Outcomes and Risks of Treatment. Am J Med. 2000;108:14-19.

45. Krakauer EL, Crenner C, Fox K. Barriers to optimum end-of-life care for minority patients. J AM Geriatr Soc. 2002;50(1):182-190.

46. Crawley LM. Racial, cultural and ethnic factors influencing end-of-life care. J Palliative Med. 2005;8:S58-S69.

47. Lyon ME, Williams PL, Woods ER, et al. Do not resuscitate orders and/or hospice care, psychological health and quality of life among children/adolescents with AIDS. J Palliative Med. 2008;11: 459-469.

48. Washington R. Press Release: Study by former DC Commissioner of mental health finds hospice care benefits black families. Montgomery Hospice June 24, 2004. Accessed January 10, 2010. Available from: http://www.montgomeryhospice.org/pdfs/20040610.pdf. [June 24, 2004].

49. Allison S, Wolters PL, Brouwers P. Youth with HIV/AIDS: Neurobehavioral consequences. In: Paul RH, Sachtor NC, Valcour V, Tashima KT, editors. HIV and the Brain, Totowa, NJ: Current Clinical Neurology, Humana Press; 2009:187-211.

50. Lyon ME, McCarter R, D'Angelo L. Detecting HIV associated neurocognitive disorders in adolescents: what is the best screening tool? J Adolesc Health. 2009;44(2):133-135.

51. Wood SM, Shah SS, Steenhoff AP, Rutstein RM. The impact of AIDS diagnoses on long-term neurocognitive and psychiatric outcomes of surviving adolescents with perinatally acquired HIV. AIDS 2009;23(14):1859-1865.

52. Lautrette A, Darmon M, Megarbane B, et al. A communication strategy and brochure for relatives of dying patients in the ICU. $N$ Engl J Med. 2007;356(5):469-478.

53. Lilly CM, DeMeo DL, Sonna LA, et al. An intensive communication intervention for the critically ill. Am J Med. 2000;109(6):469-475.

54. Lilly CM, Sonna LA, Haley KJ, Massaro AF. Intensive communication: four-year follow-up from a clinical practice study. Crit Care Med. 2003;31(5):S394-S399.

55. Romer AL, Hammes BJ. Comunication, trust, and making choices: advance care planning four years on. J Palliat Med. 2004;7:35-40.

56. Tulsky JA. Beyond advance directives: importance of communication skills at the end of life. JAMA. 2005;294(3):395-365.

57. Tulsky JA. Interventions to enhance communication among patients, providers, and families. J Palliat Med. 2005;8:S95-S102.

58. AARP. AARP North Carolina End of Life Care Survey: African American Members. Report prepared by Rachelle Cummins, MA. 2003. Accessed on January 10, 2010. Available from: http://research. aarp.org/.
59. Haas JS, Weissman JS, Cleary PD, et al. Discussion of preferences for life-sustaining care by persons with AIDS. Arch Intern Med. 1993; 153:1241-1248.

60. Emanuel EJ, Fairclough DL, Emanuel L. Attitudes and desires related to euthanasia and physician-assisted suicide among terminally ill patients and their caregivers. JAMA. 2000;284:2460-2468.

61. Thompson BL, Lawson D, Croughan-Minihane M, Cooke M. Do patients' ethnic and social factors influence the use of do-not-resuscitate orders? Ethn Dis. 1999;9:132-139.

62. Baker JN, Rai S, Lui W, et al. Race does not influence Do-Not-Resuscitate Status or the number or timing of End-of-Life discussions at a pediatric oncology referral center. J Palliat Med. 2009;12(1):71-76.

63. Bakitas M, Lyons KD, Hegel MT, et al. Effects of a palliative care intervention on clinical outcomes in patients with advanced cancer: the Project ENABLE II randomized controlled trial. JAMA. 2009;302: 746-749.

64. Davies B, Reimer JC, Brown P, Martens N. Challenges of conducting research in palliative care. Omega (Westport). 1995;31:263-273.

65. Hudson P, Aranda S. McMurray N. Randomized controlled trials in palliative care: overcoming the obstacles. Int J Palliat Nurs. 2001;7: $427-434$.

66. McMillan SC, Weitzner MA. Methodologic issues in collecting data from debilitated patients with cancer near the end of life. Oncol Nurs Forum. 2003;30:123-126.

67. Kirchhoff KT, Kehl KA. Recruiting participants in end-of-life research Am J Hosp Palliat Care. 2008;24:515-521.

68. Ingram BL, Flannery D, Elkavich A, Rotheram-Borus MJ: Common processes in evidence-based adolescent HIV prevention. Aids Behav. 2008; 12:374-383.

69. Malow RM, Kershaw T, Sipsma H, Rosenberg R, Devieux JG. HIV preventive interventions for adolescents: A look back and ahead. Curr HIV/AIDS Rep. 2007;4:173-180.

70. Tevendale HD, Lightfoot M: Programs that work: Prevention for positives. In: Lyon ME, D'Angelo LJ, editors: Teenagers HIV and AIDS: Insights from youths living with the virus Westport, CT: Praeger Publishers; 2006, p. 105-126.

71. Lyon ME, Woodward K. Nonstigmatizing ways to engage HIV-positive African-American teens in mental health and supportive services: A commentary. J Natl Med Assoc. 2003;95:196-200.

72. US Department of Health and Human Services. Call To Action: Eliminating racial and ethnic disparities in health. Washington, DC: Grantmakers in Health; 1998.

73. Dickens DS. Building competence in pediatric end-of-life care. J Palliative Med. 2009;12(7):617-622.
HIV/AIDS - Research and Palliative Care

\section{Publish your work in this journal}

HIV/AIDS - Research and Palliative Care is an international, peerreviewed open-access journal focusing on advances in research in HIV, its clinical progression and management options including antiviral treatment, palliative care and public healthcare policies to control viral spread. The journal welcomes original research, basic science,

\section{Dovepress}

clinical \& epidemiological studies, reviews \& evaluations, expert opinion \& commentary, case reports \& extended reports. The manuscript management system is completely online and includes a very quick and fair peer-review system. Visit http://www.dovepress.com/ testimonials.php to read real quotes from published authors. 